\title{
Investigating the relationship between economic growth, agricultural expansion and chemical pollution in Iran through decoupling index analysis
}

Mostafa Mardani Najafabadi

Agricultural Sciences and Natural Resources University of Khuzestan

Abbas Mirzaei ( $\square$ mabbas1369@gmail.com )

Agricultural Sciences and Natural Resources University of Khuzestan https://orcid.org/0000-00033161-3099

Somaeh Shirzadi Laskookalayeh

Sari Agricultural Sciences and Natural Resources University

Hassan Azarm

Shiraz University

\section{Research Article}

Keywords: Economic growth, Agricultural economy, Chemical pollution, Tapio decoupling model, ARDL

Posted Date: January 31st, 2022

DOI: https://doi.org/10.21203/rs.3.rs-1256565/v1

License: (9) This work is licensed under a Creative Commons Attribution 4.0 International License. Read Full License 


\section{Investigating the relationship between economic growth, agricultural expansion and chemical pollution in Iran through decoupling index analysis}

Detail of each author in this paper is:

1.

First name: Mostafa

Last name: Mardani Najafabadi

Academic rank: Assistance professor of agricultural economics

Mobil phone number: +989132309540

E-mail address: mostaf.korg@yahoo.com or m.mardani@asnrukh.ac.ir

Address: Department of Agricultural Economics, Faculty of Agricultural Engineering and Rural Development, Agricultural Sciences and Natural Resources University of Khuzestan, Mollasani, Iran.

Postal Code: 6341773637

2. (Corresponding author)

First name: Abbas

Last name: Mirzaei

Academic rank: Department of Agricultural Economics, Faculty of Agriculture Engineering and Rural Development, Agricultural Sciences and Natural Resources University of Khuzestan, Mollasani, Iran.

E-mail address: amirzaei@asnrukh.ac.ir, mabbas1369@gmail.com

Postal Code: 6341773637

Adders: Agricultural Sciences and Natural Resources University of Khuzestan, Mollasani Iran.

3.

First name: Somaeh

Last name: Shirzadi Laskookalayeh

Academic rank: Assistant Professor, Agricultural Economics Department, Sari Agricultural Sciences and Natural Resources University, Sari, Iran.

E-mail address: $\underline{\text { s.shirzadi@sanru.ac.ir or shirzady24@gmail.com }}$

4.

First name: Hassan

Last name: Azarm

Academic rank: Ph.D. student, Department of Agricultural Economics, Shiraz University, Shiraz, Iran

E-mail address: hassan_azarm@yahoo.com 


\section{Investigating the relationship between economic growth, agricultural expansion and chemical pollution in Iran through decoupling index analysis}

(1)

\section{Abstract}

The balance between the growth of the agricultural economy and the spread of pollution due to consumption of chemical inputs is one of the major challenges in agricultural sector. In this regard, the use of decoupling index to decouple the link between agricultural production and pollution caused by the consumption of chemical inputs, such as fertilizers and pesticides, is emphasized. Therefore, in the present study, the decoupling index is first calculated in relation to the emission of pollution caused by the use of chemical inputs in the process of agricultural production during the period of 1991-2016 in Iran. Then, by systematically reviewing the existing literature, the factors affecting the decoupling index in the agricultural sector of Iran are evaluated using the ARDL model. The results showed that in recent years, pollution indicators in relation to chemical inputs have not had an ideal trend and despite the further growth of agricultural production, the quality of the environment has experienced a declining trend. The results of the decoupling index related to the use of chemical pesticides and fertilizers in Iran show that during a 26-year period, only 5 and 4 years of use of these inputs have had a sustainable state compared to production growth. Also, among the factors affecting the decoupling index, the value-added variable of the agricultural sector has the most positive effect on this index and thus, increases the level of pollution in the agricultural sector in the long run. The variables of gross domestic production (GDP) and the area under cereal cultivation in the agricultural sector will also increase the decoupling index.

Keywords: Economic growth, Agricultural economy, Chemical pollution, Tapio decoupling model, ARDL

\section{Introduction}

Increased greenhouse gas emissions from human activities are a major cause of global climate change, which poses a serious threat to the well-being of human communities and ecosystems (IPCC, 2014). Agricultural production has the greatest impact on the environment after the energy sector with the emission of greenhouse gases. Net emissions from agriculture, forestry and other land uses in 2015 accounted for 24\%; while the emission rate for the energy and industry sectors is reported at 35\% and 21\%, respectively (Bonnet et al., 2018). According to the World Bank (2006), agriculture produces $70 \%$ of the world's methane (CH4), $20 \%$ of carbon dioxide $(\mathrm{CO} 2)$, and $90 \%$ of nitrous oxide (N2O) worldwide. The potential for global warming by $\mathrm{N} 2 \mathrm{O}$ and $\mathrm{CH} 4$ is 298 times and 25 times that of $\mathrm{CO} 2$, respectively (IPCC, 2006).

In recent years, the calculation of carbon emissions from agricultural land utilization (CEALU) and the discovery of factors affecting changes in CEALU have been considered by scientists (Zhou \& Hu, 2020). Most of the existing research in this field has been done for China, in this regard, we can refer to the studies of Lu et al. (2018), Zhang et 
al. 2019, Xiang and Hu, 2017, and Chen et al. (2019). Given the increase in carbon emissions as a result of agricultural production growth, the relationship between CEALU and agricultural economic growth should be given serious consideration (Zhou \& Hu, 2020; Li et al., 2019). In this regard, with the increase of environmental degradation in the agricultural sector, many researchers have considered how to decouple the link between adverse environmental outputs and favorable economic output in the agricultural sector (Tian et al., 2012; Xiong et al., 2016); this process is called decoupling (Wei et al., 2016). In 2002, the concept of decoupling in relation to economic development and environmental pollution was proposed by the OECD (Chen et al. 2017). The decoupling index means that changes in economic growth and environmental pollution should not be simultaneous (Tapio, 2005). The United Nations Environmental Program (UNEP) has called for economic growth to be decoupled from environmental impact (UNEP, 2011). According to the Sustainable Development Goals (SDGs), improving consumption and production efficiency of global resources and trying to decouple economic growth from environmental degradation should be a priority for countries (UN, 2015). Also, Qiu et al. (2018) believe that to coordinate the development of the economy and the environment, economic growth and environmental resources must be decoupled.

A review of previous literature shows that most studies in the field of decoupling index has looked at the relationship between energy use, carbon emissions, economic growth and development, and other factors (Jiang et al., 2016). In general, the decoupling index is widely used to examine the relationship between economics and ecological factors in the industry, tourism, manufacturing, and advanced industries. However, despite the high share of the agricultural sector in the spread of pollution and the appropriateness of this method to assess the relationship between the development of the agricultural economy and pollution in this industry, there is a paucity of research in this area $(\mathrm{Li}$ et al., 2019). In addition, in previous studies, carbon emissions have generally been considered as a measure of environmental pollution. However, it is important to consider agricultural indicators related to pollution, such as pesticides and the use of chemical fertilizers as agricultural production grows (Luo et al., 2017).

In modern agriculture, increasing production productivity is strongly dependent on high consumption of fertilizers and chemical pesticides, which raises concerns about the human health and environment (Zhang et al., 2019). In fact, increasing agricultural production have led to the overuse of chemical fertilizers and pesticides (Huang et al., 2018). Over the past years, crop production has become highly dependent on the use of chemical fertilizers, so that now the correlation coefficient between the use of chemical fertilizers and the production of agricultural products in the world is 0.9 (Heffer, 2009). In Iran, the quick growth of agricultural production has led to over consumption of resources and emissions.

Chemical nitrogen and phosphate fertilizers and pesticides are known as a major component of Iranian agricultural production (Hashemi et al., 2012) and play an important role in maintaining agricultural productivity. But concerns about the effects of these chemical inputs on health and the environment in Iran have been on the rise in recent years (Zare et al., 2015). The results of monitoring by the Food and Drug Administration (2016) show that in at least 10 regions of Iran, the residual amount of fertilizers and chemical toxins in many agricultural products (potatoes, onions, lettuce, cucumbers, tomatoes, apples and rice) is more than allowed. Ignorance of the principles of optimal use of 
fertilizers and chemical pesticides in farms and hazardous residues of these substances in agricultural products has led to the fact that in 2007, the World Health Organization ranked Iran 123 in the world from among 180 countries.

In general, the use of chemical pesticides and fertilizers is among the effective factors in the emission of pollutants in the agricultural sector of Iran (UNDP, 2010). However, according to the Stockholm Convention, Iran is committed to

123 limiting or eliminating the use of persistent carbon-based pollutants to protect the environment and human health

124 (Kafaei et al., 2020). Indeed, reducing pollution while maintaining economic growth can be a serious challenge for

125 Iran. In other words, the country is facing the challenge of balancing production growth in agriculture and the environment. Accordingly, evaluating the relationship between production growth and pollution in the agricultural sector and providing solutions to decouple pollution from economic growth has a significant effect on sustainable agricultural development.

However, there is a wide variety of literature on the relationship between economic growth factors, agricultural production and carbon emissions as an indicator of pollution (Ali et al., 2019). The results of Gokmenoglu and Taspinar (2018) study show that there is a two-way causal relationship between GDP and agricultural value added and CO2 emissions. In the study of Zhang et al. (2019), methods of autoregressive distributed lag (ARDL) and the vector error correction model (VECM) were used and the results presented that there is a two-way causality between carbon deoxide emissions in the agricultural sector and the growth of the agricultural economy in China. In this study, the were used. Also, Doğan (2018) used the ARDL model and concluded that agricultural production has a decisive role in CO2 emissions in the Chinese economy in the long run. Moreover, Agboola and Bekun (2019) used the ARDL method and Granger causality analysis and found that there was no relationship between agriculture and $\mathrm{CO} 2$ emissions in Nigeria between 1981 and 2014.

In addition, activities such as deforestation and the conversion of pastures into arable land for agriculture have increased global greenhouse gas emissions (Friel et al., 2009). In fact, increasing land use for crop production is one of the sources of pollution in the agricultural sector, which leads to environmental pollution (Fischer et al., 2010). A positive correlation has been established between the variables of field under cereal cultivation and agricultural value added for carbon emissions in the Jordanian economy (Ismael et al., 2018). Also, the results of Ali et al. (2019) study showed that in Pakistan for the period of 1961-2014, in the short and long term, there is a relationship between cereal crops, agricultural value added and carbon dioxide emissions. The results of this study indicated that despite the positive effect of cereals on pollution, this relationship is not statistically significant.

Furthermore, according to the review of the research literature, there has not been a comprehensive study on the causal relationship between decoupling index in the agricultural sector and macroeconomic and social variables. Therefore, discovering variables affecting changes in decoupling index can provide useful information to planners, policy makers and stakeholders (Pao \& Chen, 2019). However, some researchers have used decomposition analysis to examine the factors affecting the decoupling index (Zhao et al., 2016; Wang et al., 2018; Dong et al., 2021). The combination of been performed in various studies (Zhang and Da, 2015; Román et al. 2018; Wang and Feng, 2019). For example, Wang et al. (2019) analyzed the factors influencing the decoupling situation in China's industrial sector and found that 
GDP per capita and population prevent decoupling, but energy intensity accelerates the decoupling process. Dong et al. (2021) used decomposition analysis to identify the factors affecting these indices by creating a new decoupling index and comparing it with the main decoupling index. The results showed that GDP per capita and emission coefficient have positive and negative effects on both indicators, respectively. In the study of Pao and Chen (2019) also was examined the causal relationship between economy, emissions, energy, and the strategy of decoupling environmental pressure from economic growth. They stated that absolute economic decoupling ${ }^{1}$ is necessary in order to create sustainable economic growth and thus, increase energy efficiency and reduce pollution emissions.

A systematic review of the existing literature revealed that despite the high share of the agricultural sector in the spread of pollution and the appropriateness of the decoupling method to assess the relationship between agricultural economic growth and pollution in this sector, there are few studies in this area. In most previous studies, environmental pollutions have been measured based on carbon dioxide emissions (Sinha and Shahbaz, 2018). However, considering the agricultural indicators related to the pollution caused by pesticides and the use of chemical fertilizers is more consistent with reality (Li et al., 2019). No study has been found regarding the calculation of decoupling index in Iran's agricultural sector. On the other hand, a review of studies shows that no comprehensive study has been conducted to estimate the causal relationship between macro variables and decoupling index in the agricultural sector.

According to the above, in this study, the first goal is to evaluate the relationship between the growth of agricultural production value and pollution caused by the production process in this sector in Iran using agricultural production data and the use of chemical inputs as an indicator of pollution. To this end, decoupling index has been used in which

173 the per capita variables of GDP value, chemical fertilizer and pesticides uses are considered. In fact, by examining

174 this index, the most important question of this study will be answered: "is there a balance between the growth of agricultural production and the environment in Iran?" Accordingly, the first hypothesis is that the growth of agricultural economy and environment in Iran is not coordinated and further growth of agricultural production has led 177 to increased pollution.

178 The second goal is to evaluate the causal relationship between the environmental index of decoupling and the variables 179 affecting this index in the agricultural sector. In order to achieve this goal, an answer must be found to this question: "which of the variables affecting pollution in the agricultural sector in Iran has the greatest impact?" The second hypothesis of the present study is that among the variables affecting the changes in the decoupling index in recent years, the value added of the agricultural sector has had a greater impact on the rate of this index.

\section{Materials and Methods}

185 This study was performed in two phases, a schematic view of which is shown in Figure 1. In the first phase of the 186 present study, the decoupling index of the relationship between agricultural production growth and pollution caused

\footnotetext{
${ }^{1}$ Absolute decoupling occurs when the pressure on a sustainable environment is declining and the driving forces of the economy are increasing.
} 
by the production process in this sector in Iran was first evaluated using the Tapio decoupling model. By calculating this index, different states of the decoupling index were identified during different years. In the second phase, the causal relationship between the decoupling index and the variables affecting it in the agricultural sector was investigated using ARDL model.

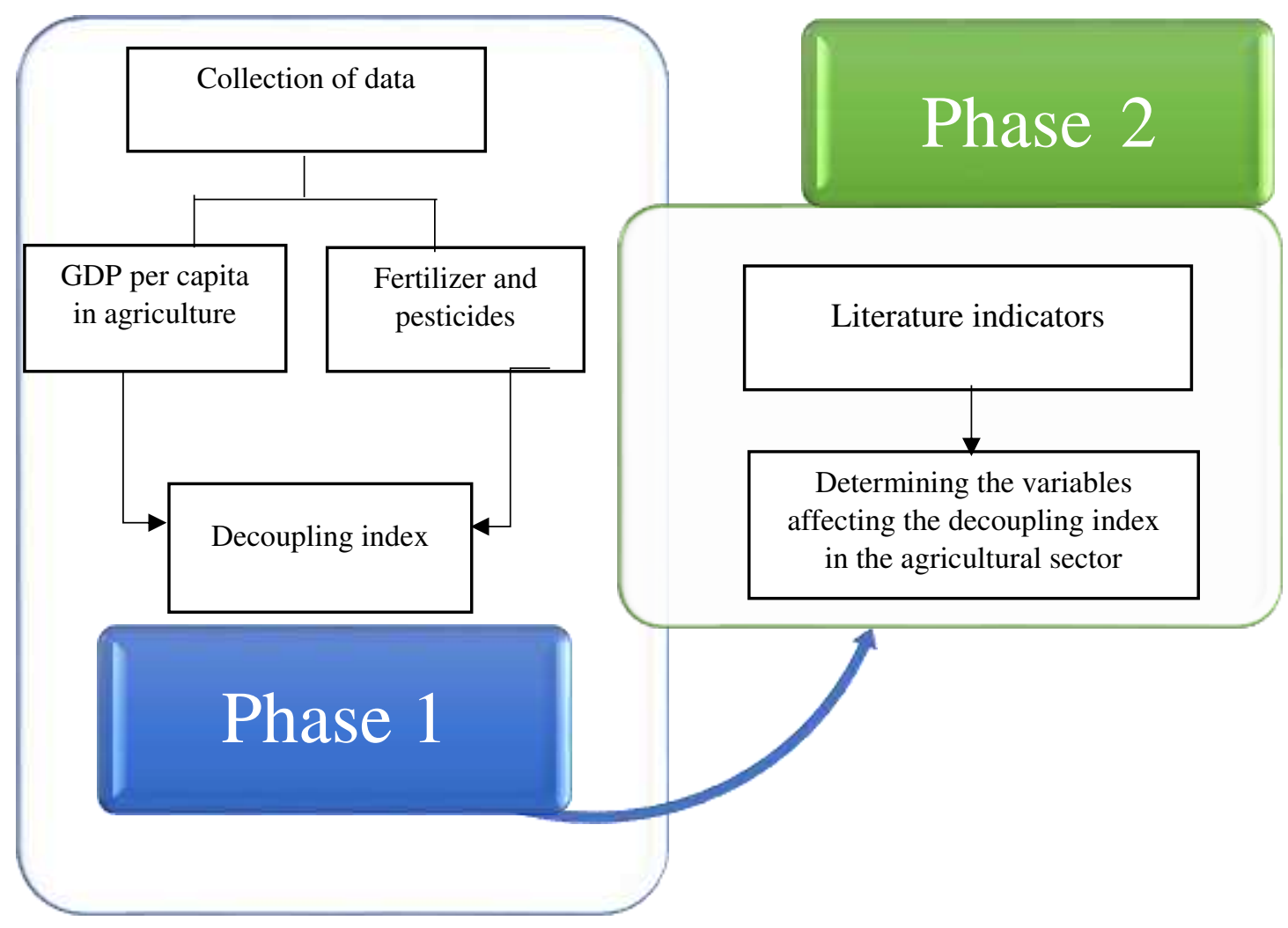

Figure 1- Flowchart of the present research methodology

\subsection{Decoupling index}

It is possible to quantity the relationships and asynchronous changes between environmental pressure, resource consumption, and economic growth using the decoupling index (Long and Wang, 2017). In a given period, there is a decoupling relationship between economic growth, environmental pressure and resource consumption, if the economic growth rate is greater than the environmental degradation rate due to economic activities (Yi et al., 2014). The absolute and relative decoupling index has been used by the Organization for Economic Co-operation and Development (OECD) in agricultural policy research (OECD, 2005). The status of economic growth decoupling and carbon 
comprehensiveness and compatibility of this model (Wang and Zhang, 2021; Kong et al., 2021). In this regard, Tapio (2005) defined eight decoupling modes that are reported in Table 1.

204 Strong decoupling (absolute decoupling) discusses the steady or decreasing state of environmental variables in relation to economic growth. Weak decoupling (relative decoupling) indicates an increase in resource consumption and environmental pressure which is less than economic growth (Zhang, 2013). The per capita value of GDP is a desirable criterion for reflecting economic growth in agriculture; because this variable shows the total scale of local agricultural production growth (Dou et al., 2016). Also in the past literature, indicators of pesticide use and agricultural fertilizers have been used as indicators of pollution in the agricultural sector (Zahm et al., 2008; Li et al., 2019b).

The decoupling index can be calculated by Equation 1:

$211 D_{i}=\frac{\Delta P_{i}}{P_{i}} / \frac{\Delta G}{G}$

212 In this equation, $D_{i}$ signifies the decoupling index between the economy and pollution pollution criteria in the 213 agricultural sector. $G$ and $P_{i}$ are the per capita value of GDP and agricultural pollution criteria, respectively. The 214 variables $\Delta \mathrm{G}$ and $\Delta \mathrm{P}$ also show changes of per capita value of agricultural GDP and agricultural pollution criteria,

215 respectively. In addition, $\frac{\Delta G}{G}$ and $\frac{\Delta P_{i}}{P_{i}}$ represent the rate of change in per capita value of GDP and agricultural pollution 216 indicators, respectively (OECD, 2005).

217 In this study, $\mathrm{D}_{1}$ (when $\mathrm{i}=1$ ) and $\mathrm{D}_{2}$ (when $\mathrm{i}=2$ ) show the decoupling index for chemical pesticide and fertilizer, 218 respectively. Due to the difference of decoupling coefficients, the division of this index into 8 minor states is presented 219 in Table 1. Table 1- Decoupling modes based on decoupling index

\begin{tabular}{llccc}
\hline & \multicolumn{1}{c}{ State } & \multicolumn{2}{c}{ Index } \\
\hline & & $\frac{\Delta P_{i}}{P_{i}}$ & $\frac{\Delta G}{G}$ & $\mathrm{D}_{\mathrm{i}}$ \\
\hline \multirow{2}{*}{ Negative decoupling } & Expansive negative decoupling & + & + & $\mathrm{D}_{\mathrm{i}}>1.2$ \\
\cline { 2 - 4 } & Strong negative decoupling & + & - & $\mathrm{D}_{\mathrm{i}}<0$ \\
\cline { 2 - 4 } & Weak negative decoupling & - & + & $0 \leq \mathrm{D}_{\mathrm{i}}<0.8$ \\
\hline Decoupling & Weak decoupling & - & + & 0.8 \\
\cline { 2 - 4 } & Strong decoupling & - & $\mathrm{D}_{\mathrm{i}}<0.8$ \\
\cline { 2 - 4 } & Recessive decoupling & - & $\mathrm{D}_{\mathrm{i}}>1.2$ \\
\hline Connection & Expansive connection & + & + & $0.8 \leq \mathrm{D}_{\mathrm{i}} \leq 1.2$ \\
\cline { 2 - 4 } & Recessive connection & - & - & $0.8 \leq \mathrm{D}_{\mathrm{i}} \leq 1.2$ \\
\hline
\end{tabular}


Strong decoupling is the most ideal situation for development, which states that the growth rate of production is positive and the growth rate of consumption of chemical inputs is negative. Weak decoupling shows that the growth rate of chemical inputs consumption is lower than the growth rate of output value. The worst-case scenario is widespread negative decoupling, in which the production and consumption of chemical inputs both grow simultaneously, but the consumption of inputs grows faster than the value of production.

Statistics and information on the chemical fertilizers and pesticides uses in the agricultural sector, as well as the value of per capita GDP, were obtained from the FAO statistical database.

\subsection{Determining the variables affecting decoupling index in the agricultural sector}

In line with the goal of the second phase of the research (study of the factors affecting the decoupling index in the agricultural sector), it is necessary to first specify the econometric model based on economic theories and research. Since the variables affecting the decoupling index may be affected by the time interval or may be affected by this index itself, it seems appropriate to use multivariate time series patterns to determine the factors affecting the decoupling index. Because in these models, it is assumed that a variable cannot be explained only by its past and there is other information that is effective in explaining the behavior of the variable.

The most important issue in using time series patterns is to choose the right pattern from the wide range of these patterns in order to have a better prediction. This choice is usually made based on the characteristics of the time series and how they relate to each other. Accordingly, first the variables that the researcher thinks and often have a possible relationship based on economic theories and previous studies, are considered as vectors of the initial model variables. Then, since the presence of a unit root in each of the pattern variables is one of the statistically important features of the studied variables, it is examined using tests such as Dickey-Fuller or Phillips-Perrron to determine their order of co-integration. Finally, the type of causal relationship between the pattern variables must be identified and the appropriate pattern should be selected based on it (Fomby, 1998).

In the present study, the relationship between the variables of GDP, value added of the agricultural sector and the area under cultivation of cereal of decoupling index in the agricultural sector of Iran has been investigated. The data required for this section is provided by the FAO and World Bank databases. The definition of study variables is presented in Table 2. 
Table 2- Definition of study variables

\begin{tabular}{cccc}
\hline Variable & Definition & Unit & Source \\
\hline $\boldsymbol{D}_{\boldsymbol{t}}$ & Decoupling index in the agricultural & $\%$ & $\begin{array}{c}\text { First phase calculations } \\
\text { sector }\end{array}$ \\
\hline $\boldsymbol{G D} \boldsymbol{P}_{\boldsymbol{t}}$ & Gross Domestic Product per capita & GDP per capita, PPP (constant & WDI \\
& & 2011 international \$ & \\
\hline $\boldsymbol{A} \boldsymbol{V} \boldsymbol{A}_{\boldsymbol{t}}$ & Agriculture value added & Million dollars & FAOSTAT \\
\hline $\boldsymbol{L} \boldsymbol{C} \boldsymbol{C}_{\boldsymbol{t}}$ & Area under cereal cultivation & Hectare & WDI \\
\hline
\end{tabular}

257 Several techniques are adopted to investigate the causal relationship. In this study, long-term and short-term effects between the studied variables were investigated using ARDL method.

Accordingly, in the first phase of the study, time series data were first checked to ensure the absence of spurious stationary regression. For this purpose, Augmented Dickey-Fuller (ADF) and Phillips-Perron (P-P) tests were used. In the second step, the optimal lag length of the studied variables was determined using the Schwarz Information Criterion (SC). According to Ivanov and Kilian (2005) and Phillips and Ploberger (1994) the SC criterion is more appropriate for models with a sample size of less than 120. In the next step, the presence or absence of long-term relationship between the variables was assessed using the bound test. The model was estimated after ensuring a longterm relationship.

The ARDL method allows the study of both long-term and short-term effects between variables. In other words, this method has the ability to estimate long-term and short-term components simultaneously. The limitations of analysis based on the Engle-Granger method led some studies to overcome the shortcomings of the above method in order to achieve a better approach for analyzing the long-run relationship between variables. Among these studies is the study of Pesaran et al. (1995) and Pesaran and Shin (1996). The approach presented by them, in addition to eliminating the need for information about the relationship between variables, allows the study of the relationship between variables

272 when some of them are stationary and others become stationary with a differential load. This approach is called the

273 ARDL approach. The main advantage of this strategy is that it can be used regardless of whether the variables are 274 stationary at the level or stationary after one differentiation, and this advantage makes it difficult to divide the variables 275 into groups of cointegrated stationary and stationary after one differentiation. This method has the ability to estimate 276 short-term and long-term components simultaneously, and also because these models are generally free of problems 277 such as serial correlation and endogenously, the estimates obtained from them will be unbiased and efficient.

278 The augmented ARDL model in the present study can be written as Equation 2:

279

$\alpha(l, p) Y_{t}=\alpha_{0}+\sum_{i=1}^{k} \beta_{i}(l, q) X_{i t}+u_{t}$ 
Where, ${ }^{\alpha}$ is intercept, $Y_{t}$ is the dependent variable, $\mathrm{X}_{\mathrm{it}}$ is the $\mathrm{i}^{\text {th }}$ independent variable, and $\mathrm{L}$ is lag operator defined as $L^{j} Y_{t}=Y_{t-j}$. If equation 3 is expressed as the following equations:

$$
\alpha(L, p)=1-\alpha L^{1}-\ldots-\alpha_{p} L^{p}, \quad \beta_{i}(L, q)=\beta_{i 0}+\beta_{i 1} L+\beta_{i 2} L^{2}+\ldots+\beta_{i q} L_{i}^{q}
$$

Then, in the long run, Equation (4) will be true between the variables in the model:

$$
Y_{t}=Y_{t-1}=\ldots=Y_{t-p}, \quad X_{i, t}=X_{i, t-1}=\ldots=X_{i, t-q}
$$

Where, $\mathrm{q}$ is the lag number corresponding to the $\mathrm{i}^{\text {th }}$ variable. The long-run relationship between the variables can be expressed as Equation 5.

$$
Y=\alpha+\sum_{i=1}^{k} \beta_{i} X_{i}+v_{i} \quad, \quad \alpha=\frac{\alpha_{0}}{\alpha(1, p)} \quad \beta_{i}=\frac{\beta_{i}(1, q)}{\alpha(1, p)}=\frac{\sum_{j=0}^{q} \beta_{i}}{\alpha(1, p)} \quad, \quad v_{i}=\frac{u_{t}}{\alpha(1, p)}
$$

The ARDL model error correction equation is written as Equation 6:

$Y_{t}=\Delta \alpha_{0}^{\wedge}-\sum_{j=2}^{p} \alpha_{j}^{\wedge} \Delta Y_{t-j}+\sum_{i=0}^{k} \beta_{i 0}^{\wedge} \Delta X_{i t}-\sum_{i=1}^{k} \sum_{j=1}^{q} \beta_{i, t-j}^{\wedge} \Delta X_{i, t-j}-\alpha(1, p) E C T_{t-1}+u_{t}$

Where, ECT (error correction term) is defined as follow:

$$
E C T=Y_{t}-\alpha-\sum_{i=1}^{k} \beta_{i} X_{i t}
$$

In which, $\alpha$ and $\beta$ are the estimated coefficients of the equation under study, and $\alpha(1, p)$ measures the speed of adjustment and represents the coefficient of error correction term. The statistical basis for the use of error correction models is the existence of convergence between a set of economic variables. These patterns have become more and more common in experimental work. Relating short-term fluctuations of variables to their long-run equilibrium values is the main reason for the popularity of ECT models.

297 Accordingly, the econometric model of the present study is specified as Equation 8:

$298 \quad \ln D_{t}=f\left(G D P_{t}, A V A_{t}, L C C_{t}\right)$

299 Natural logarithm has been used in order to evaluate the long-run relationship between the studied variables. By 300 logarithmzing the variables, the assurance of efficiency, stability and consistency of the results increases. The 301 logarithmic form of the model will be as equation 9 .

$\ln D_{t}=\alpha_{1} \ln G D P_{t}+\alpha_{2} \ln A V A_{t}+\alpha_{3} \ln L C C_{t}+\varepsilon_{t}$ 
Parameters $\alpha 1$ to $\alpha 3$ show the long-term elasticity of the decoupling index relative to the independent variables and $\varepsilon_{\mathrm{t}}$ is also the error term of the regression model.

It is noteworthy that due to the fact that the amount of carbon emissions per kilogram of chemical toxins is more than 5.5 times the amount of chemical fertilizers (West and Marland, 2002; ORNL, 2016), to investigate the relationship between chemical toxin and fertilizers' decoupling index in this study, the decoupling index is aggregated by weight average and by giving more weight to the decoupling index, which reflects the consumption status of chemical pesticides and the value of per capita production.

In addition, according to the divided states of the decoupling index, this index is multifaceted, and it is not possible to comment on the increase or decrease of pollution with the positive or negative sign of this index. In fact, the sign of changes in the consumption of chemical inputs and per capita production value are the determining criteria for environmental quality from the point of view of the decoupling index. For example, if the decoupling index value is negative, both the worst case scenario and the best case scenario for environmental quality may be achieved. In addition, in the case of a positive decoupling index, the smaller the numerical value of this index, the lower the level of pollution from agricultural products. Thus, in order to investigate the factors affecting the decoupling index, uniform and one-way orientation of the decoupling index is inevitable. In this regard, data normalization will be useful to prevent the classification and continuity of decoupling index data. Normalization is an operation that is performed on raw data and puts the data in the same domain by rescaling or transforming. There are many ways to normalize data in a given domain based on statistical operations. The Minimum - Maximum Value Based Normalization (MMVBN) method uses the minimum or maximum values of non-normalized data to rescale.

322 The Min - Max Normalization (MMN) method is one of the most widely used MMVBN methods that classifies 323 abnormal data at a high and low boundary within a predetermined range (Han et al., 2011). In fact, each data is 324 converted to a range of 0 to 1 according to the minimum (min) and maximum (max) values. The general formula for

325 MMN to convert the data to a range of 0 to 1 is presented in Equation (10).

327 Here, $\mathrm{z}$ is transformed or normal data, $\mathrm{x}$ is also non-normal data or data that is to be normalized, and min and max represent the minimum and maximum of $\mathrm{i}^{\text {th }}$ value, respectively. Also, nmin and nmax show the lower and upper bounds for rescale data, respectively.

\section{Results}

The results of the decoupling index for pollution caused by agricultural products were presented in Table 3 . The results of chemical pesticide decoupling index in Iran show that during a 26-year period (1991 to 2016), only 5 years of chemical pesticide use has been in a stable state and there is a strong decoupling for the value of GDP per capita in 
agricultural products, the use of chemical pesticides has decreased. Widespread negative decoupling was repeated in 4 years. This means that the growth of consumption of chemical inputs is faster than the growth of production value, and these conditions led to an increase in polluted production.

339 Strong negative decoupling also occurred at 5 years. In such circumstances, changes in the value of agricultural production are decreasing, but changes in the use of chemical pesticides are increasing. Weak decoupling has also occurred for 6 years. Thus, the growth rate of chemical pesticide consumption and per capita production value have been both positive, but the growth rate of chemical pesticide consumption is lower. On the other hand, between 1998 and 2000, there was a strong negative decoupling, which shows a positive growth in pesticide consumption and a negative growth in the value of agricultural production, and leads to an increase in the spread of pollution. In case of weak negative decoupling, although both variables of growth rate of production value and consumption of chemical toxins are negative, but the rate of reduction of toxin input consumption is less than the decrease of production value, which can also lead to worsening environmental conditions and reduced production. Recessive decoupling also occurred in 5 years and indicates a lower decline in the value of agricultural production compared to the decline in the use of chemical pesticides.

The decoupling index situation for the use of chemical fertilizers also shows that in the years 2009 to 2011 and 2015, the severity of pollution was in a favorable condition. In other words, the decoupling index is in a strong decoupling situation and the rate of chemical fertilizer consumption was negative and the growth value of agricultural products was positive. Extensive negative decoupling has occurred in 2 years, which indicates that the production and consumption of chemical inputs are both growing at the same time, but the growth of consumption of this input is faster than the growth of production value, when production was more and pollution was increasing. This has been the case for the decoupling index in relation to chemical toxins for 4 years. Also, recessive decoupling in relation to chemical fertilizer use and production value occurred in 1993 and 2007. This situation has occurred for the chemical fertilizers use and the growth of agricultural production in 7 years. In fact, the occurrence of this condition means high consumption of resources and high emission of pollution. In any case, the decoupling index of chemical fertilizers and GDP per capita does not follow a specific trend during different years. Figure 2 and 3 clearly show the fluctuations of this index for the years under review.

Table 3- decoupling index status for each of the indicators of fertilizer and chemical pesticide consumption (1991 to 2016)

\begin{tabular}{|c|c|c|c|c|c|c|c|}
\hline Year & $\frac{\Delta \boldsymbol{G}}{\boldsymbol{G}}$ & $\frac{\Delta P_{1}}{P_{1}}$ & $D_{1}$ & $\begin{array}{l}\text { Decoupling index for the } \\
\text { chemical pesticides }\end{array}$ & $\frac{\Delta \boldsymbol{P}_{2}}{\boldsymbol{P}_{2}}$ & $D_{2}$ & $\begin{array}{l}\text { Decoupling } \\
\text { index for the } \\
\text { chemical } \\
\text { fertilizers }\end{array}$ \\
\hline 1991 & 0.062158 & 0.535983 & 8.623 & Expansive negative & 0.179 & 2.879 & $\begin{array}{l}\text { Expansive } \\
\text { negative }\end{array}$ \\
\hline
\end{tabular}




\begin{tabular}{|c|c|c|c|c|c|c|c|}
\hline 1992 & -0.03249 & -0.2854 & 8.783 & Recessive & 0.268024 & -8.248 & Strong negative \\
\hline 1993 & -0.06521 & -0.18069 & 2.771 & Recessive & -0.33482 & 5.134 & Recessive \\
\hline 1994 & 0.19578 & 0.078562 & 0.401 & Weak & 0.097297 & 0.496 & Weak \\
\hline 1995 & -0.0974 & -0.15285 & 1.569 & Recessive & 0.039409 & -0.404 & Strong negative \\
\hline 1996 & -0.16012 & -0.39039 & 2.438 & Recessive & 0.082504 & -0.515 & Strong negative \\
\hline 1997 & 0.253659 & 0.190548 & 0.751 & Weak & 0.211317 & 0.833 & $\begin{array}{l}\text { Expansive } \\
\text { connection }\end{array}$ \\
\hline 1998 & -0.14543 & 0.16005 & -1.101 & Strong negative & 0.057799 & -0.397 & Strong negative \\
\hline 1999 & -0.1471 & 0.137968 & -0.938 & Strong negative & -0.0344 & 0.233 & Weak negative \\
\hline 2000 & -0.0151 & 0.121122 & -8.019 & Strong negative & 0.017424 & -1.153 & Strong negative \\
\hline 2001 & 0.239798 & -0.04119 & -0.172 & Strong & 0.017781 & 0.074 & Weak negative \\
\hline 2002 & -0.01394 & 0.064831 & -4.651 & Strong negative & 0.096067 & -6.891 & Strong negative \\
\hline 2003 & 0.119558 & 0.055984 & 0.468 & Weak & 0.054015 & 0.451 & Weak \\
\hline 2004 & 0.075247 & -0.01125 & -0.150 & Strong & 0.045216 & 0.600 & Weak \\
\hline 2005 & 0.268325 & -0.22037 & -0.821 & Strong & 0.044092 & 0.164 & Weak \\
\hline 2006 & 0.206227 & -0.2801 & -1.358 & Strong & 0.06078 & 0.294 & Weak \\
\hline 2007 & -0.0096 & -0.05327 & 5.595 & Recessive & -0.03362 & 3.501 & Recessive \\
\hline 2008 & 0.178348 & -0.49063 & -2.751 & Strong & 0.068474 & 0.385 & Weak \\
\hline 2009 & 0.126076 & 0.342393 & 2.716 & Expansive negative & -0.13375 & -1.060 & Strong \\
\hline 2010 & 0.112862 & 0.081975 & 0.726 & Weak & -0.08726 & -0.773 & Strong \\
\hline 2011 & 0.310459 & 0.075764 & 0.244 & Weak & -0.40765 & -1.313 & Strong \\
\hline 2012 & 0.059781 & 0.495969 & 8.296 & Expansive negative & 0.19915 & 3.331 & $\begin{array}{c}\text { Expansive } \\
\text { negative }\end{array}$ \\
\hline 2013 & -0.12554 & -0.07913 & 0.630 & Weak negative & -0.06609 & 0.526 & Weak negative \\
\hline 2014 & -0.08203 & 0.017863 & -0.218 & Strong negative & 0.120571 & -1.469 & Strong negative \\
\hline 2015 & 0.014686 & 0.017549 & 1.195 & Expansive negative & -0.19594 & -13.342 & Strong \\
\hline 2016 & 0.029345 & 0.017098 & 0.583 & Weak & 0.001522 & 0.051 & Weak \\
\hline
\end{tabular}




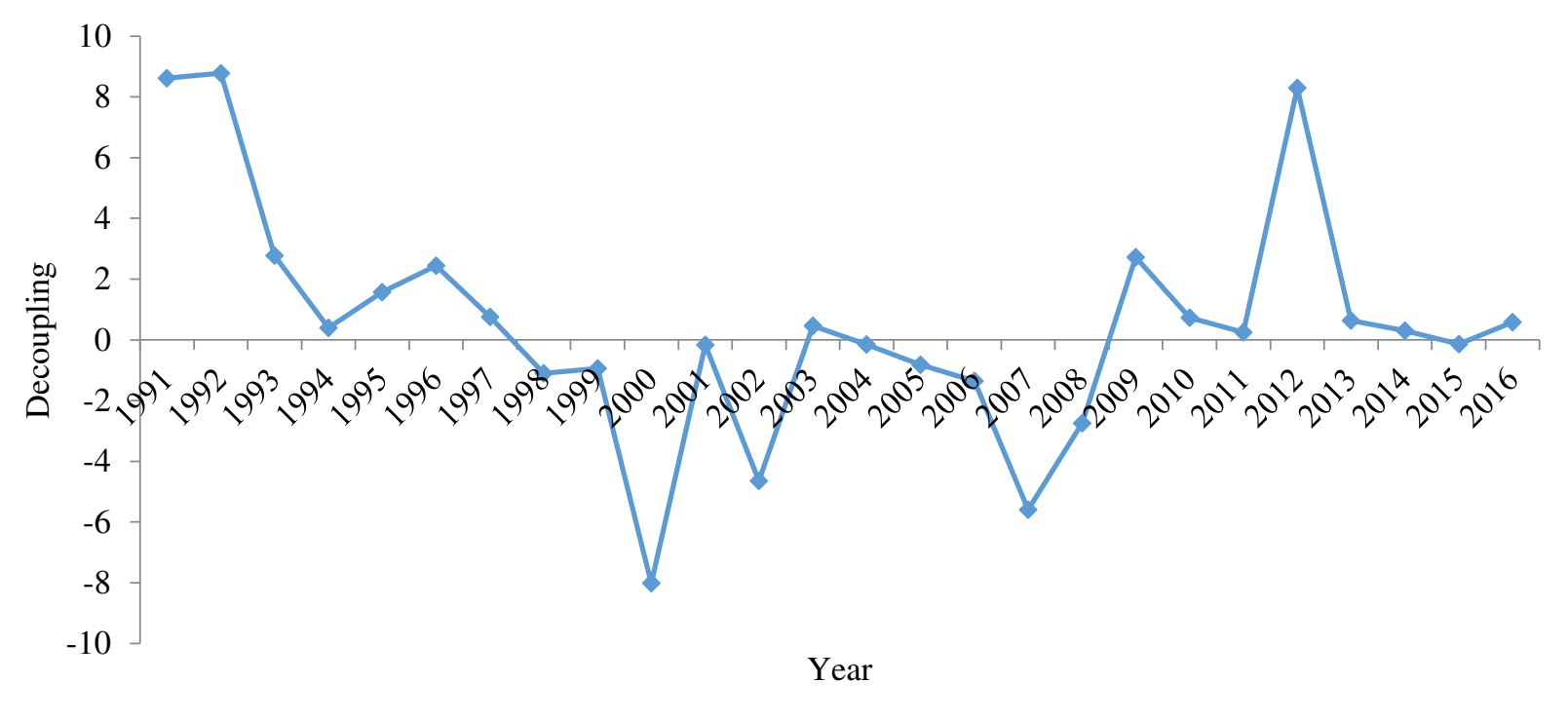

Figure 2- Changes in the chemical pesticide decoupling index for the period 1991-2016

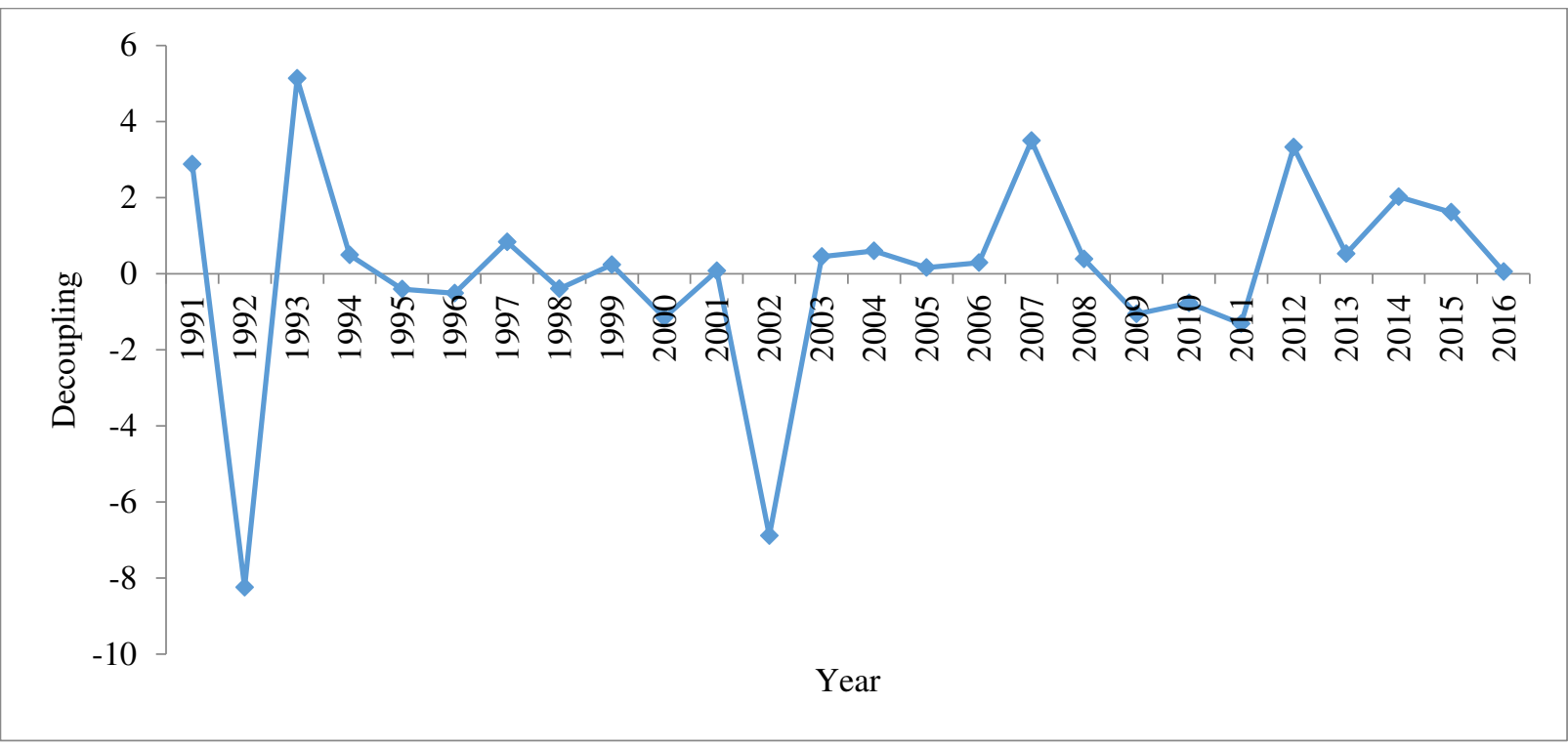

Figure 3- Changes in chemical fertilizer decoupling index for the period 1991-2016

373 Then, the effective factors on the decoupling index in the agricultural sector of Iran were evaluated. In order to

374 investigate these factors, the stationary state of variables was first tested. It is worth mentioning that in order to avoid 375 spurious regression, it is necessary to make sure that the variables are stationary in the period under study before 376 estimating the pattern. For this purpose, the Phillips-Perron (P-P) and augmented Dickey-Fuller (ADF) tests were 377 used, the results of which are reported in Table 4. The results show that the variables of decoupling index and GDP 
are at stationary level. The value-added variables of the agricultural sector and the area under cereal cultivation are also stationary with one time differentiation. The results of the Phillips-Perron test also confirm the results of the ADF test. It is worth noting that a maximum lag of 6 was considered and the optimal ADF test lag was selected based on Schwartz-Bayesian criteria. Newey-West Bandwidth was used for the P-P test.

Table 4: Stationary test of variables using ADF and P-P

\begin{tabular}{|c|c|c|c|c|c|c|}
\hline \multirow[b]{2}{*}{ Variables } & \multicolumn{3}{|c|}{$\mathrm{ADF}$} & \multicolumn{3}{|c|}{ P-P } \\
\hline & T-statistic & Lag & Stationary & Adj. t-stat & Bandwidth & Stationary \\
\hline $\ln D$ & $-4.92^{* * *}$ & 0 & $\mathrm{I}(0)$ & $-5.02^{* * *}$ & 4 & $\mathrm{I}(0)$ \\
\hline $\ln G D P$ & $-3.28^{* * *}$ & 1 & $\mathrm{I}(0)$ & $-4.22^{* * *}$ & 4 & $\mathrm{I}(0)$ \\
\hline $\ln A V A$ & $-5.20^{* * *}$ & 0 & $\mathrm{I}(1)$ & $-6.18^{* * *}$ & 4 & $\mathrm{I}(1)$ \\
\hline $\ln L C C$ & $-5.08^{* * *}$ & 0 & $\mathrm{I}(1)$ & $-5.10^{* * *}$ & 2 & $\mathrm{I}(1)$ \\
\hline
\end{tabular}

$(* * *$ shows significance at the level of $1 \%)$.

Due to the presence of stationary variables at the level and variables that become stationary after one time differentiation, the ARDL method has been used. First, it is essential to assessment the existence of a long-run relationship between variables. The bound test was used in order to check for a long-term relationship. The null hypothesis of the bound test is based on the absence of a long-run relationship between variables, the results of which are reported in Table 5. Given that the computational F statistic of the specified model is greater than the upper limit at the level of $1 \%$, so the null hypothesis is rejected and the existence of a long-run relationship between the variables is confirmed.

Table 5- Result of long-term relationship test between variables (bound test)

\begin{tabular}{|c|c|c|c|c|c|c|c|}
\hline \multirow[t]{3}{*}{ Model } & \multirow[t]{3}{*}{$\mathrm{F}$} & \multicolumn{6}{|c|}{ Critical values } \\
\hline & & \multicolumn{2}{|c|}{0.10} & \multicolumn{2}{|c|}{0.05} & \multicolumn{2}{|c|}{0.01} \\
\hline & & $\mathrm{I}(0)$ & $\mathrm{I}(1)$ & $\mathrm{I}(0)$ & $\mathrm{I}(1)$ & $\mathrm{I}(0)$ & $\mathrm{I}(1)$ \\
\hline $\ln D_{t}=f\left(\ln G D P_{t}, \ln A V A_{t}, \ln L C C_{t}\right)$ & $7.91^{* * * *}$ & 3.47 & 4.45 & 4.01 & 5.07 & 5.17 & 6.36 \\
\hline
\end{tabular}

The results of estimating the long-run relationship in the model are summarized in Table 6. The ARDL model (1, 0, $0,1)$ was selected as the optimal model based on Schwartz-Bayesian statistics. of this index will mean cleaner production, so the positive effect of the studied variables on this index will mean an 
increase in pollution from agricultural production. According to the results of estimating the long-run relationship in Table 6, it can be seen that the coefficient of GDP per capita variable is positive and significant. In other words, the growth of the whole economy has been accompanied by an increase in pollution in the agricultural sector. So that with a $1 \%$ increase in GDP, with other conditions being constant, the decoupling index increases by $0.14 \%$.

404 The relationship between the value added of the agricultural sector and the decoupling index is positive in the long run. The coefficient of this variable is numerically larger than other variables. In other words, the results indicate that the decoupling index variable is elastic to the value added of the agricultural sector. Therefore, this variable will have a greater effect on increasing the decoupling index and creating polluted production than other existing variables. So that with a $1 \%$ increase in the value added of the agricultural sector, the decoupling index increases by more than $1 \%$.

The results also indicate that there is a significant and positive relationship between the area under cereal cultivation and pollution in the agricultural sector. Based on the estimated coefficients, with a $1 \%$ increase in the area under cereal cultivation, with other conditions being constant, the decoupling index in the agricultural sector increases by $0.23 \%$.

Table (6) also presents the results of the error correction model. Except for the coefficient of variable of value added of the agricultural sector, other estimated coefficients are negative in the short run and indicate a decrease in the decoupling index. Therefore, GDP in the short run did not have a significant effect on the decoupling index. The variable of area under cereal cultivation and its lag in the short term has negative effects on the decoupling index. In other words, if the area under cereal cultivation increases, the decoupling index will decrease next year. In addition, similar to the long-term case, the effect of value added of the agricultural sector on the decoupling index in the short run is also positive. In general, the sign and significance of the coefficients of variables in the short term is very different from the long term. Of course, the value of most coefficients of variables is not very significant in the short run and is not far from zero. In fact, the effect of these variables on the changes in the decoupling index is not significant, which seems obvious because the effect of each of these variables requires the passage of time.

The ECT term coefficient shows what percentage of the short-term imbalance of the decoupling index is adjusted to achieve the long-term equilibrium in each period; in other words, this coefficient indicates how long it takes for the decoupling index to return to its long-term trend. The estimated ECT coefficient in the model is statistically significant and indicates a relatively low adjustment rate. In fact, according to the coefficient of error correction term, it can be said that in each period, $14 \%$ of the variable deviations of the decoupling index in the agricultural sector disappears and in case of a shock to the model, short-term equilibrium approached to long-term equilibrium after more than 7 years.

Table 6- Results of long-term and short-term relationship of factors affecting the decoupling index in Iran's agricultural sector

\begin{tabular}{ccc}
\hline Variables & \multicolumn{2}{c}{ Long-run coefficients } \\
\hline $\operatorname{lnGDP}$ & $0.14^{* * *}$ & 3.35 \\
\hline
\end{tabular}




\begin{tabular}{clc}
\hline $\ln \mathbf{A V A}$ & $1.09^{* * *}$ & 4.22 \\
\hline $\ln \mathbf{C} C$ & $0.23^{* * *}$ & 2.03 \\
\hline $\mathbf{C}$ & Short-run coefficients & 5.61 \\
\hline$\Delta(\ln \boldsymbol{G D P})$ & $-0.98^{* * *}$ & -1.56 \\
\hline$\Delta(\ln \mathbf{C C})$ & -0.09 & -2.18 \\
\hline$\Delta(\ln \mathbf{L C}(-\mathbf{1}))$ & $-0.03^{* *}$ & -3.36 \\
\hline$\Delta(\ln \mathbf{A V A})$ & $-0.12^{* * *}$ & 4.15 \\
\hline$\Delta(\ln \mathbf{A V A}(-\mathbf{1}))$ & $0.04^{* * *}$ & 4.58 \\
\hline $\boldsymbol{E} \boldsymbol{C} \boldsymbol{T}_{\boldsymbol{t}-\mathbf{1}}$ & $0.15^{* * *}$ & -7.04
\end{tabular}

433 Figures 3 and 4 show the cumulative sum (CUSUM) and sum of cumulative squares (QCUSUM) tests, respectively.

434 According to the statistical chart of the above tests in the 95\% confidence interval, the estimated coefficients of the 435 model are stable.

436

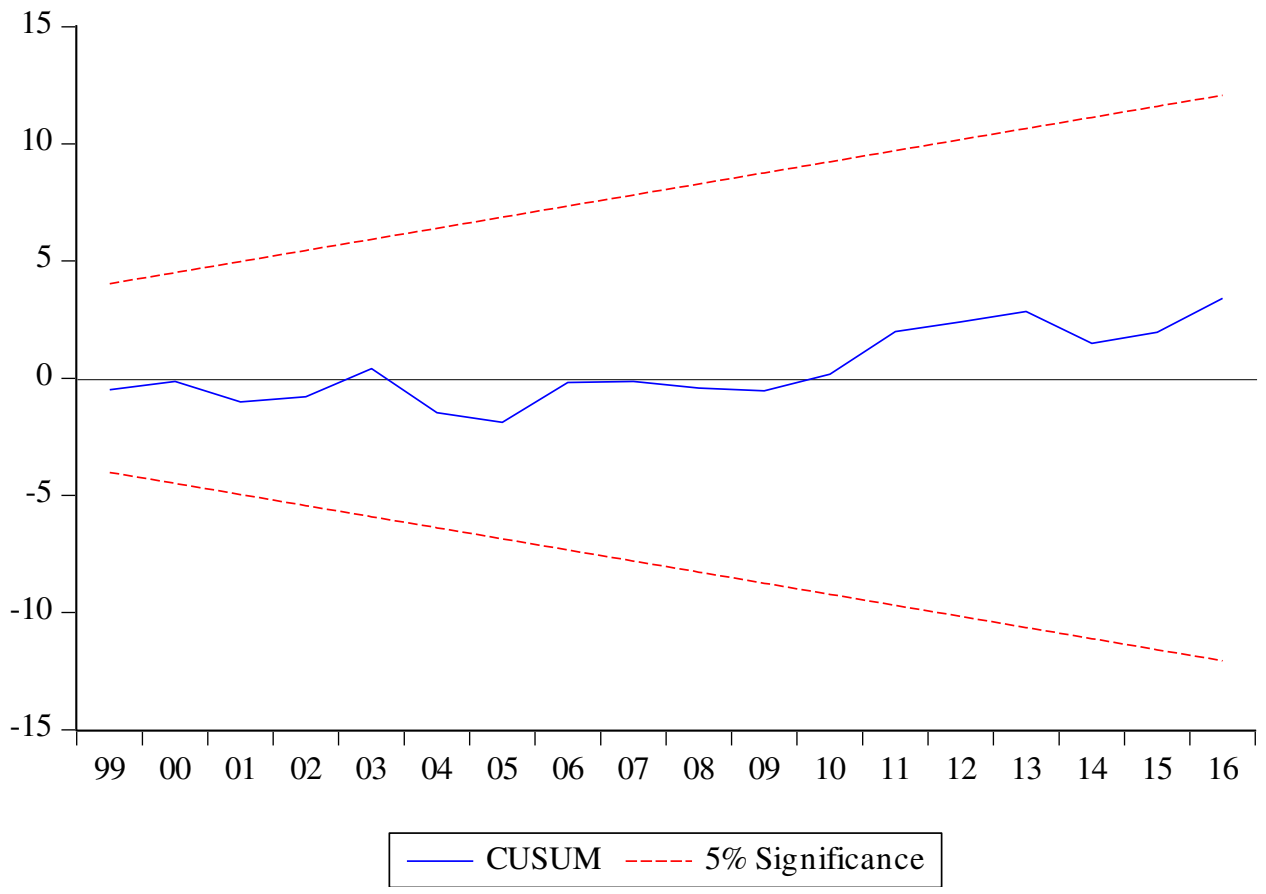

Figure 3- Cumulative sum test 


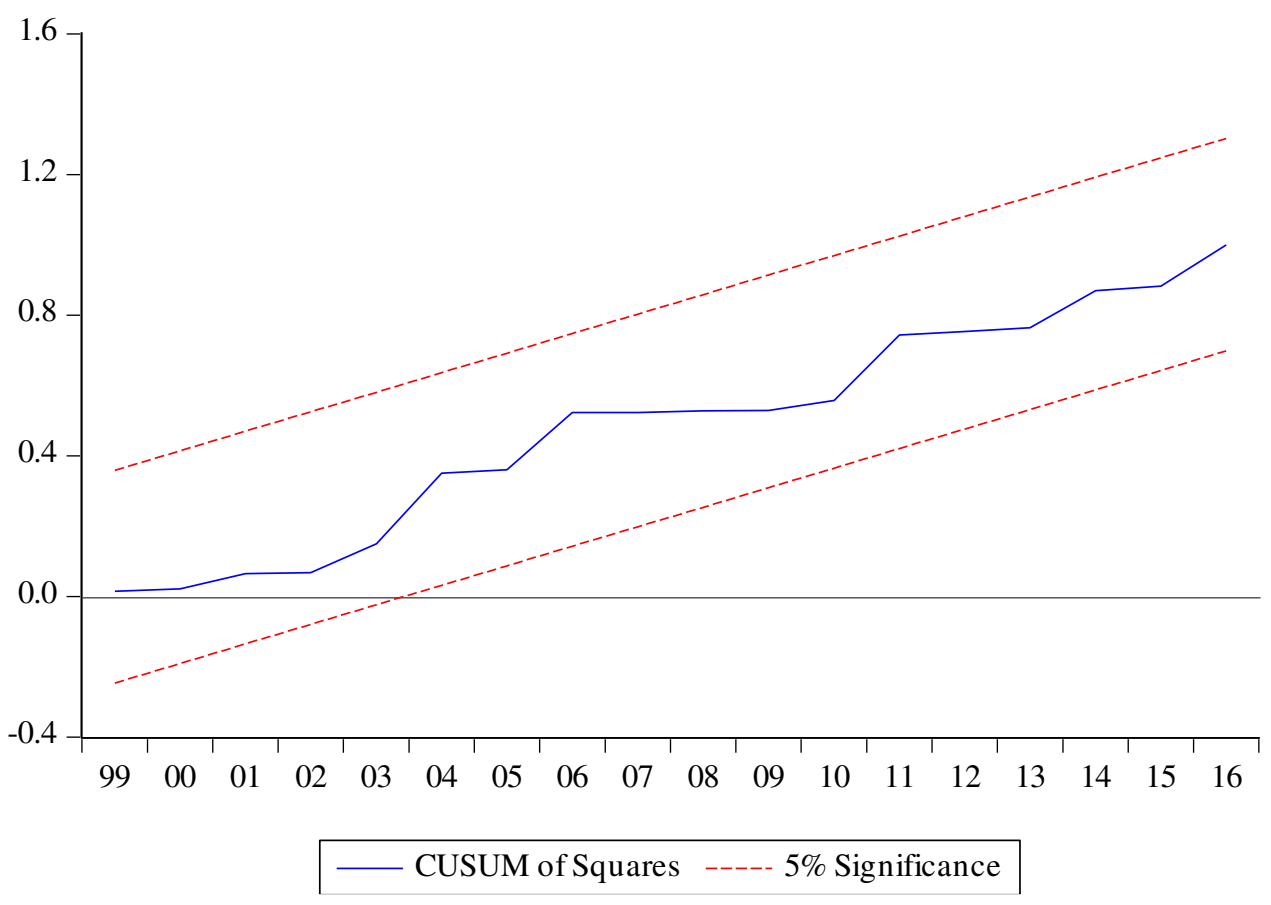

Figure 4- Sum of cumulative squares test (QCUSUM)

\section{Discussion}

443 In this section, the comparison of the results with other researches and the main hypotheses of the study are discussed 444 and finally, some limitations and future studies are presented.

\subsection{Hypothesis 1: Lack of coordination in the growth of environment and agricultural economy in Iran}

446 The results of decoupling the process of agricultural production and pollution caused by the use of chemical inputs 447 showed that the agricultural economy growth by increasing the consumption of pesticides and chemical fertilizers has 448 led to environmental pollution in Iran. However, the strong negative decoupling of the Tapio decoupling index is one 449 of the worst possible situations in relation to environmental issues, and the achievement of this result indicates a 450 significant imbalance between production growth and environmental quality in Iran's agricultural sector. Therefore, 451 the results of calculating the Tapio decoupling elasticity showed that there is no balance between the growth of 452 agricultural economy and environment in Iran and further growth of agricultural production has led to increased 453 pollution. In this regard, the first hypothesis of the study that there is no coordination between production growth in 454 agriculture and environmental quality in Iran is accepted.

455 Various studies around the world have pointed to a mismatch between the agricultural economy growth and the spread 456 of pollution in the environment. In this regard, Zhang et al. (2019) stated that the use of chemical pesticides while 457 increasing the yield of agricultural products has negative externalities on human health and ecological conditions. In 458 fact, pollution caused by the use of chemical fertilizers and pesticides in addition to severe pollution of fields has led 
to deterioration of nitrogen and phosphorus and the entry of other organic or inorganic pollutants into surface and groundwater, which endangers the health of the environment and humans (Liu, 2008; Dou et al., 2016). Continuation of these conditions with environmental degradation can limit economic development ( $\mathrm{Li}$ et al., 2020). Zhong et al. (2012) used the decoupling index to examine the relationship between economic growth and resource consumption and concluded that for development process in China has paid a lot of environmental costs in the past. The decoupling index has also been used in the examination of economic growth and sustainability concept. Long \& Wang (2017) employed this index and stated that environmental pollution due to economic growth will reduce the level of welfare of society in China. De Freitas \& Kaneko (2011) also examined the main causes of increased pollution by decoupling the growth rate of economic activity and greenhouse gas emissions in Brazil. They stated that several periods of decoupling had been observed in Brazil, with the largest decoupling occurring in 2009.

In relation to the use of decoupling index in agricultural production and pollution caused by the use of chemical inputs, Li et al. (2009) calculated decoupling index for pesticide consumption and agricultural per capita GDP in Chengdu, China, and found that during the period of 2009-2017, the ideal situation of "strong decoupling" has occurred in six

472 years. However, the chemical fertilizers uses for five years has ideally "strong decoupling". In general, contrary to the results of the present study, with the growth of agricultural economy in Chengdu, pesticides and fertilizers have been reduced and the development of agricultural economy and environment in this region is coordinated.

\subsection{Hypothesis 2: Significant effect of value added in agriculture on decoupling index}

477 The results of the bound test showed the existence of a stable long-term pattern between the decoupling index as an indicator of pollution and the selected variables based on previous theories. In examining the long-term model for the estimated model, all variables had a positive and significant effect on the decoupling index. So that increasing economic growth, area under cereal cultivation and value added of the agricultural sector in the long run will lead to an increase in the decoupling index and thus, increase pollution caused by the use of chemical inputs. Considering the positive and significant coefficient of variable of GDP per capita in the long run, it can be concluded that economic growth in Iran will increase the decoupling index in the agricultural sector and thus, reduce the quality of the environment. Therefore, the second hypothesis of the present study that the value added of the agricultural sector from among the variables affecting the changes in the decoupling index in recent years will have a greater impact on the rate of this index, is accepted.

Past studies have shown a positive relationship between increased GDP and carbon dioxide emissions as an indicator of environmental pollution (Gokmenoglu and Taspinar, 2018). Also, the results of the present study showed that in the long run, there is a positive relationship between the value added of the agricultural sector and the decoupling index in this sector. The positive effect of this variable on the spread of pollution has been proven in the study of Zhang et al. (2019) and Yurtkuran (2021). The results of the study by Gokmenoglu and Taspinar (2018) showed that the value added of the agricultural sector had a positive and inelastic effect on greenhouse gas emissions in Pakistan. 
Jebl \& Youssef (2017) concluded that increasing GDP and increasing the value added of the agricultural sector will lead to increased $\mathrm{CO} 2$ emissions in selected North African countries.

It is worth mentioning that other variables also had a significant effect on the pollution index. For example, the variable of area under cereal cultivation also had a positive effect on the decoupling index and thus, reduced the quality of the environment in the agricultural sector of Iran. In this regard, Ismael et al. (2018) concluded that the growth of the area under cereal cultivation and agricultural value added have an increasing effect on carbon emissions in the Jordanian economy. This finding indicates that the trend of expanding the area under cereal cultivation in Iran in recent years has been very rapid and the conversion of different types of uses (forests and pastures) into agricultural land has led to increased emissions of pollutants. On the other hand, a significant increase in the area under cultivation of agricultural products in Iran and as a result, excessive consumption of chemical inputs has led to severe pollution of farms (UNDP, 2010). According to FAO (2016) statistics, the area under cereal cultivation in Iran during the years 1961 to 2016 has experienced a growth of nearly 80 percent. However, in the period under review, the average growth of the area under cereal cultivation in the world was close to $42 \%$. Accordingly, increasing the area under cultivation of agricultural products has increased the demand for chemical inputs, which has led to more pollution in Iran's agricultural sector.

Finally, it is worth noting that in the present study, due to the limitations of the data, only the use of chemical inputs was considered as a polluting variable in relation to the decoupling index in Iran, but considering more indicators such as the use of plastic in agriculture or energy consumption in different stages of crop production can be effective in better depicting the situation of pollution and production growth. In addition, despite the high potential of the decoupling index in assessing the balance between production growth and pollution in the agricultural sector, not many studies have been conducted in this field. On the other hand, more research is needed to identify and examine the variables affecting changes in the agricultural sector's decoupling index as a comprehensive environmental indicator.

\section{Conclusion}

In recent years, the decoupling index in relation to chemical inputs has not had an ideal trend, and despite the overall growth of Iran's agricultural economy, the quality of the environment has decreased in most years. Continuing the increasing use of chemical fertilizers and pesticides, while polluting water, soil and air and adding heavy metals and threatening public health, will endanger development, food security and public health. Therefore, reducing pollution should be a priority of Iran's agricultural environmental policies. Improving the relationship between the decoupling of growth of the agricultural economy requires a gradual and long-term process in a country or region. To achieve an ideal decoupling of pollution and economic growth in the agricultural sector, adopting strategies to improve resource efficiency will be key. Accordingly, increasing investment in research and development and improving relations with developed countries in order to introduce modern and environmentally friendly technologies is essential to reach sustainable development of the agricultural sector. Investing in building green infrastructure in the agricultural sector 
and moving towards the application of low carbon technologies can help coordinate economic growth and environmental quality in Iran. In fact, the advancement of agricultural technologies with increasing production per unit area will reduce land use for a certain amount of production, which will reduce the consumption of resources, including chemical inputs at the farm level. Also, policy-making and planning for the implementation of biotechnological methods with the aim of reducing pollution in the agricultural sector should be a priority of Iran's environmental policies. In addition, the use of a set of incentive and punishment tools to oblige agricultural producers to maintain the quality of the environment can also be helpful. For example, a higher tax on conventional fertilizers, while exempting taxes on organic fertilizers and pesticides, could reduce the use of conventional chemical inputs in terms of supply. In terms of demand, subsidizing organic fertilizers encourages farmers to use this type of fertilizer.

\section{Author contribution}

Mostafa Mardani Najafabadi: Supervision, Visualization, Conceptualization. Abbas Mirzaei: Methodology, Software, Validation. Somayeh Shirzadi laskookalayeh: Investigation, Writing - review \& editing. Hasan Azarm: Data curation, Writing- Original draft preparation.

\section{Data availability}

544 The datasets used during the current study are available from the corresponding author on request.

\section{Declarations}

\section{Ethics approval}

548 Not applicable.

\section{Consent to participate}

550 Not applicable.

\section{Consent for publication}

552 Not applicable.

\section{3 competing interests}

554 The second, third and fourth authors state that they have no competing financial interests. The first author has received 555 a research grant from Research and Technology Deputy of Agricultural Sciences and Natural Resources University of 556 Khuzestan. Also, personal relationships that could have appeared to influence the work reported in this research. 


\section{Funding}

559 This study is a part of research "Analysis of the relationship between production and pollution in Iran's agricultural

560 sector using the decoupling index" with the support of the Research and Technology Deputy of Agricultural Sciences 561 and Natural Resources University of Khuzestan [grant numbers 1400.04], Iran.

\section{References}

564

565Ahmed, Z., Zafar, M. W., Ali, S., 2020. Linking urbanization, human capital, and the ecological footprint in G7 countries: 566 an empirical analysis. Sustainable Cities and Society, 55, 102064.

567Al-Mulali, U., Ozturk, I., 2015. The effect of energy consumption, urbanization, trade openness, industrial output, and the 568 political stability on the environmental degradation in the MENA (Middle East and North African) region. Energy. $569 \quad 84,382-389$.

570Appiah, M. O., 2018. Investigating the multivariate Granger causality between energy consumption, economic growth and $571 \quad$ CO2 emissions in Ghana. Energy Policy. 112, 198-208.

572Bonnet, C., Bouamra-Mechemache, Z., Corre, T., 2018. An environmental tax towards more sustainable food: empirical 573 evidence of the consumption of animal products in France. Ecological Economics. 147, 48-61.

574Chen, B., Yang, Q., Li J., Chen G., 2017. Decoupling analysis on energy consumption, embodied GHG emissions and 575 economic growth - The case study of Macao. Renewable and Sustainable Energy Reviews. 67, 662-672.

576Chen, X., Shuai, C., Zhang, Y., Wu, Y., 2020. Decomposition of energy consumption and its decoupling with economic $577 \quad$ growth in the global agricultural industry. Environmental Impact Assessment Review. 81, 106364.

578Chen, Y. H., Li, M. J., Su, K., Li, X. Y., 2019. Spatial-temporal characteristics of the driving factors of agricultural carbon $579 \quad$ emissions: Empirical evidence from Fujian, China. Energies. 12, 3102.

580De Freitas, L., Kaneko, S., 2011. Decomposing the decoupling of $\mathrm{CO} 2$ emissions and economic growth in Brazil. $581 \quad$ Ecological Economics. 70, $1459-1469$.

582Deng, X., Gibson, J., Wang, P., 2017. Quantitative measurements of the interaction between net primary productivity and 583 livestock production in Qinghai Province based on data fusion technique. Journal of Cleaner Production. 142, $584 \quad 758-766$.

585Destek, M.A., Sarkodie, S.A., 2019. Investigation of environmental Kuznets curve for ecological footprint: the role of 586 energy and financial development. Sci. Total Environ. 650, 2483-2489.

587Doğan, N., 2018. The impact of agriculture on CO2 emissions in China. Panoeconomicus, 66(2), 257-271.

588Dong, F., Li, J., Zhang, X., Zhu, J. 2021. Decoupling relationship between haze pollution and economic growth: A new 589 decoupling index. Ecological Indicators. 129, 107859.

590Dou, Y., Deng, Y., Chen, S., 2016. Current situation of agricultural environmental pollution in China and technological $591 \quad$ innovation path for its control. Sci. Manag. Res. 34, 76-79.

592Fischer, G., Winiwarter, W., Ermolieva, T., Cao, G. Y., Qui, H., Klimont, Z., Wagner, F., 2010. Integrated modeling

593 framework for assessment and mitigation of nitrogen pollution from agriculture: Concept and case study for

594 China. Agriculture, ecosystems \& environment. 136(1-2), 116-124.

595Fomby, B.T., 1998. How to Model Multivariate Time Series Data, Department of Economics, Southern Methodist $596 \quad$ University, Dallas.

597Fuglie, K. O., 2018. Is agricultural productivity slowing?. Global food security. 17, 73-83.

598Gujarati, D., 2004. Basic econometrics, Fourth Edition. The McGraw-Hill Companies.

599Han, J., Pei, J., Kamber, M., 2011. Data mining: concepts and techniques. Elsevier.

600Hashemi S.M, Hosseini S.M, Hashemi M.K., 2012. Farmers' perceptions of safe use of pesticides: Determinants and 601 training needs. Int Arch Occup Environ Health. 85:57-66. 
602Heffer, P., Prud-homme, M., 2009. Medium-term outlook for global fertilizer demand, supply and trade: 2009-2013. In 603 Proceedings 77th IFA Annual Conference, 25th -27 th May, Shangha, China.1-12.

604Huang, H., Bai, C., Yi, X., 2018. Financial exclusion, agricultural science and technology investment and agricultural 605 economic development. Manag World. 34, 67-78.

606Intergovernmental Panel on Climate Change (IPCC), 2006. IPCC Guidelines for National Greenhouse Gas Inventories. $607 \quad$ www.ipcc-ggip.iges.

608IPCC, 2014. Summary for policymakers: Impacts, Adaptation, and Vulnerability, Climate Change 2014: Impacts, 609 Adaptation, and Vulnerability. Part A: Global and Sectoral Aspects. Intergovernmental Panel on Climate Change, $610 \quad$ United Kingdom and New York, NY, USA.

611Iran Food and Drug Administration, 2016. Available at https://www.fda.gov.ir/en. (Unpublished)

612Ismael, M., Srouji, F. Boutabba, M.A., 2018. Agricultural technologies and carbon emissions: evidence from Jordanian

613 economy. Environ Sci Pollut Res. 25, 10867-10877.

614Ivanov, V., Kilian, L., 2005. A practitioner's guide to lag order selection for VAR impulse response analysis, Studies in $615 \quad$ Nonlinear Dynamics and Econometrics, 9, 1-34.

616Jain, A., Nandakumar, K., Ross, A., 2005. Score normalization in multimodal biometric systems. Pattern recognition.

$61738(12), 2270-2285$.

618Jebli, M. B., Youssef, S. B., 2017. The role of renewable energy and agriculture in reducing CO2 emissions: Evidence for 619 North Africa countries. Ecological indicators. 74, 295-301.

620Jiang, X. T., Dong, J. F.,Wang, X. M., Li, R. R., 2016. The multilevel index decomposition of energy-related carbon 621 emission and its decoupling with economic growth in USA. Sustainability. 8, 857.

622Kafaei, R., Arfaeinia, H., Savari, A., Mahmoodi, M., Rezaei, M., Rayani, M., Ramavandi, B., 2020. Organochlorine 623 pesticides contamination in agricultural soils of southern Iran. Chemosphere, 240, 124983.

624Kong, Y., He, W., Yuan, L., Zhang, Z., Gao, X., Degefu, D. M., 2021. Decoupling economic growth from water 625 consumption in the Yangtze River Economic Belt, China. Ecological Indicators. 123, 107344.

626Li, M., Wang, J., Chen, Y., 2019. Evaluation and influencing factors of sustainable development capability of agriculture 627 in countries along the Belt and Road route. Sustainability. 11.

628Li, S., Gong, Q., Yang, S., 2019. Analysis of the agricultural economy and agricultural pollution using the decoupling 629 index in Chengdu, China. International journal of environmental research and public health. 16(21), 4233.

630Liu, Y., 2008. Prevention and control measures of agricultural pollution in China. Macroecon. Manag. 7, 58-60.

631Long, L., Wang, X., 2017. A study on the relationship among ecological loss, economic growth and welfare level in the 632 process of urbanization in China: Based on Tapio decoupling analysis and Granger Causality Test. Inq. Into Econ. $633 \quad 3,98-106$.

634Lu, X. H., Kuang, B., Li, J., Han, J., Zhang, Z., 2018. Dynamic evolution of regional discrepancies in carbon emissions 635 from agricultural land utilization: Evidence from Chinese provincial data. Sustainability. $10,552$.

636Luo, Y., Long, X., Wu, C., Zhang, J., 2017. Decoupling CO2 emissions from economic growth in agricultural sector across 63730 Chinese provinces from 1997 to 2014. Journal of Cleaner Production. 159, 220-228.

638Ma, M. D., Cai, W. G., 2019. Do commercial building sector-derived carbon emissions decouple from the economic growth 639 in Tertiary Industry? A case study of four municipalities in China. Science of The Total Environment. 650, 822640834.

641Oak Ridge National Laboratory, 2016. Available at https://www.ornl.gov.

642OECD, 2005. Effects of Quantitative Constraints on the Degree of Decoupling of Crop Support Measures; OECD: Paris, $643 \quad$ France, 2005.

644Pao, H. T., Chen, C. C., 2019. Decoupling strategies: CO2 emissions, energy resources, and economic growth in the Group 645 of Twenty. Journal of cleaner production. 206, 907-919.

646Phillips, P.C., Ploberger, W., 1994. Posterior odd Testing for a unit root with data based Model selection, Econometric 647 Theory. (10), 774-808.

648Qiu, F., Shen, Z., Zhang, J., 2011. Dynamic analysis of sustainable development of coal city based on decoupling model: 649 A case study of Xuzhou city. Areal Res. Dev. 30, 67-72.

650Román-Collado, R., Cansino, J. M., Botia, C., 2018. How far is Colombia from decoupling? Two-level decomposition

651 analysis of energy consumption changes. Energy. 148, 687-700. 
652Sharif, A., Baris-Tuzemen, O., Uzuner, G., Ozturk, I., Sinha, A., 2020. Revisiting the role of renewable and non-renewable 653 energy consumption on Turkey's ecological footprint: evidence from Quantile ARDL approach. Sustainable $654 \quad$ Cities and Society. 57, 102-138.

655Siddiki, J. U., 2000. Demand for money in Bangladesh: A cointegration analysis, Applied Economics. 32(15), 1977-1984. 656Singh, D., Singh, B. 2020. Investigating the impact of data normalization on classification performance. Applied Soft

657 Computing. 97, 105524.

658Sinha, A., Shahbaz, M., 2018. Estimation of environmental Kuznets curve for CO2 emission: role of renewable energy 659 generation in India. Renewable energy. 119, 703-711.

660Tapio, P., 2005. Towards a theory of decoupling: Degrees of decoupling in the EU and the case of road traffic in Finland 661 between 1970 and 2001. Transport Policy. 12, 137-151.

662Tian, Y., Zhang, J.B., Li, B., 2012. Research on agricultural carbon emission in China: calculation, spatial-temporal 663 comparison and decoupling effect. Resour. Sci. 34 (11). 2097-2105.

664Uddin, G. A., Salahuddin, M., Alam, K., Gow, J., 2017. Ecological footprint and real income: Panel data evidence from 665 the 27 highest emitting countries. Ecological Indicators. 77, 166-175.

666UN, 2015. Sustainable Development Goals. https://sustainabledevelopment.un.org/.(Accessed September 2018).

667UNEP, 2011. Decoupling natural resource use and environmental impacts from economic growth. In: Fischer-Kowalski, 668 M., Swilling, M., von Weizs€acker, E.U., Ren, Y., Moriguchi, Y., Crane, W., Krausmann, F., Eisenmenger, N., 669 Giljum, S., Hennicke, P., Romero Lankao, P., Siriban Manalang, A., Sewerin, S. (Eds.), A Report of the Working 670 Group on Decoupling to the International Resource Panel. United Nations Environment Programme, Paris.

671UNFCCC, 2015. UNFCCC Country Brief 2014: Iran (Islamic Republic of). Retrieved from 672 http://newsroom.unfccc.int/unfccc-newsroom/iran-submits-its-climate-action-plan-ahead-of-2015-

673 parisagreement/.

674Waheed, R., Chang, D., Sarwar, S., Chen, W., 2018. Forest, agriculture, renewable energy, and CO2 emission. Journal of

675 Cleaner Production. 172, 4231-4238.

676Wang, M., Feng, C., 2019. Decoupling economic growth from carbon dioxide emissions in China's metal industrial sectors:

677 A technological and efficiency perspective. Science of The Total Environment. 691, 1173-1181.

678Wang, Q., \& Zhang, F., 2021. The effects of trade openness on decoupling carbon emissions from economic growth679 evidence from 182 countries. Journal of cleaner production. 279, 123838.

680Wang, Q., Zhang, F. Y., 2020. Does increasing investment in research and development promote econo,mic growth 681 decoupling from carbon emission growth? An empirical analysis of BRICS countries. Journal of Cleaner $682 \quad$ Production. 252, 119853.

683Wang, Q., Zhao, M., Li, R., Su, M., 2018. Decomposition and decoupling analysis of carbon emissions from economic

684 growth: A comparative study of China and the United States. Journal of Cleaner Production. 197, 178-184.

685Wei, J., Zhou, J., Tian, J.L., He, X.B., Tang, K.L., 2006. Decoupling soil erosion and human activities on the Chinese $686 \quad$ Loess Plateau in the 20th century. Catena. 68, 10-15.

687West, T.O., Marland, G., 2002. A synthesis of carbon sequestration, carbon emissions, and net carbon flux in agriculture: 688 comparing tillage practices in the United States. Agric. Ecosyst. Environ. 91, 217-232.

689World Bank, 2016. World Development Indicators: Agricultural Nitrous Oxide Emissions. $690 \quad$ http://data.worldbank.org/indicator/EN.ATM.NOXE.AG.ZS.

691World Bank, 2018. World Development Indicators: Agricultural Methane Emissions. [Dataset]. Available at 692 https://data.worldbank.org/indicator/EN.ATM.METH.KT.CE (accessed Jan 20, 2020).

693Wu, Y., Tam, V. W. T., Shuai, C. Y., Shen, L. Y., Zhang, Y., Liao S. J., 2019. Decoupling China's economic growth from 694 carbon emissions: Empirical studies from 30 Chinese provinces (2001-2015). Science of the Total Environment. $695 \quad 656,576-588$.

696Wu, Y., Zhu, Q., Zhu, B., 2018. Decoupling analysis of world economic growth and CO2 emissions: A study comparing 697 developed and developing countries. Journal of Cleaner production. 190, 94-103.

698Xiang, L., Hu, L., 2017. Decoupling analysis of regional high-tech industry cluster and ecological environment. Forum 699 Sci Technol. 06, 101-108. 
700Xiong, C. H., Yang, D. G., Hua, J. W., Zhao, Y. N., 2016. The relationship between agricultural carbon emissions and 701 agricultural economic growth and policy recommendations of a low-carbon agriculture economy. Polish Journal 702 of Environmental Studies. 25, 2187-2195.

703Xiong, C.H., Yang, D.G., Huo, J.W., Zhao, Y.N., 2016. The relationship between agricultural carbon emissions and 704 agricultural economic growth and policy recommendations of a low-carbon agriculture economy. Pol. J. Environ. $705 \quad$ Stud. $25(5), 2187-2195$.

706Xu, B., Lin, B. Q., 2017. Factors affecting CO2 emissions in China's agriculture sector: Evidence from geographically $707 \quad$ weighted regression model. Energy Policy. 104, 404-414.

708Yi, P., Fang, S., Ma, C. 2014. Decoupling Evaluation of Tourism Economic Growth and Eco-environmental Pressure in 709 Geoparks: A Case Study of Songshan Mountain World Geopark. J. Nat. Resour. 29. 1282-1296.

710Zahm, F., Viaux, P., Vilain, L., Girardin, P., Mouchet, C., 2008. Assessing farm sustainability with the IDEA method711 from the concept of agriculture sustainability to case studies on farms. Sustain. Dev. 16, 271-281.

712Zare, S., Behzadi, M., Tarzanan, M., Mohamadi, M. B., Omidi, L., Heydarabadi, A. B., Kazemi, S., 2015. The impacts of 713 pesticides on the health of farmers in Fasa, Iran. Electronic physician. 7(4), 1168.

714Zhang, J., Wang, J., Zhou, X., 2019. Farm Machine Use and Pesticide Expenditure in Maize Production: Health and 715 Environment Implications. International journal of environmental research and public health. 16(10), 1808.

716Zhang, Y., 2013. Research on the Decoupling Distribution of Energy Consumption, Carbon Dioxide Emissions and 717 Sustainable Development of China's Industry. Res. Dev. 1, 104-108.

718Zhang, Y. J., Da, Y. B., 2015. The decomposition of energy-related carbon emission and its decoupling with economic

719 growth in China. Renewable and Sustainable Energy Reviews. 41, 1255-1266.

720Zhang, Z. X., 2000. Decoupling China's carbon emissions increase from economic growth: an economic analysis and 721 policy implications. World Development. 28, 739-75.

722Zhang, Z., Xue, B., Pang, J., Chen, X., 2016. The Decoupling of Resource Consumption and Environmental Impact from 723 Economic Growth in China: Spatial Pattern and Temporal Trend. Sustainability. 8, 222.

724Zhao, X., Zhang, X., Shao, S., 2016. Decoupling CO2 emissions and industrial growth in China over 1993-2013: the role

725 of investment. Energy Economics. 60, 275-292.

726Zhong, W., Sun, Y., Qing, D., 2012. Research on Decoupling relationship between economic growth, energy consumption 727 and carbon dioxide emissions. J. Audit Econ. 27, 99-105.

728Zhou, M., Hu, B., 2020. Decoupling of carbon emissions from agricultural land utilisation from economic growth in China. 729

730

731

732 